\title{
RESPONSABILIDADE OBJETIVA DAS PESSOAS JURÍDICAS NA LEI No 12.846/13: O INTERESSE COMO CRITÉRIO NORMATIVO E O CONFLITO DE INTERESSES COMO OBJETO DE COMPLIANCE
}

\author{
Murilo Thomas Aires ${ }^{1}$ \\ Camila Yano Sato ${ }^{2}$
}

\section{RESUMO}

Observando-se o papel central da responsabilidade objetiva na Lei Anticorrupção brasileira, e a presença de critérios de imputação objetiva que a delimita, o presente trabalho teve como objetivo analisar o interesse da pessoa jurídica preconizado no artigo $2^{\circ}$, apoiando-se na doutrina societária. Buscou-se ainda abordar a questão do conflito de interesses, e como este pode ser objeto do principal instrumento preventivo indicado pelas normas anticorrupção: o compliance. Concluiu-se pela característica construtiva do conceito de interesse, e pelo importante papel do conflito de interesses como instrumento de prevenção da responsabilidade objetiva, e dos próprios atos lesivos em si.

PALAVRAS-CHAVE: RESPONSABILIDADE OBJETIVA, PESSOA JURÍDICA, INTERESSE SOCIAL, CONFLITO DE INTERESSES, COMPLIANCE.

\section{STRICT LIABILITY OF LEGAL ENTITIES IN THE BRAZILIAN LAW No 12.846/13: THE INTEREST AS NORMATIVE STANDARD AND THE CONFLICT OF INTERESTS AS A COMPLIANCE ISSUE}

\begin{abstract}
Observing the central role of strict liability in the responsibility system of the legal entity in Law 12.846/13, and the few criteria of objective imputation that delimits it, this study analyzes what would be the interest of the entity on Article 2, based on the studies developed by corporate law doctrine. The conflict of interest issue is addressed as the subject of the main preventive instrument indicated by the anticorruption rules: compliance. The conclusion adopted the constructive characteristic of the concept of interest, and that compliance programs are an important instrument to prevent strict liability and harmful acts.
\end{abstract}

\footnotetext{
${ }^{1}$ Mestrando pela Faculdade de Direito de Ribeirão Preto da

Universidade de São Paulo (FDRP/USP)

${ }^{2}$ Mestranda pela Faculdade de Direito de Ribeirão Preto da Universidade de São Paulo (FDRP/USP)
} 
KEYWORDS: STRICT LIABILITY, LEGAL ENTITY, BUSINESS CORPORATION, CONFLICT OF INTERESTS, COMPLIANCE.

\section{INTRODUÇÃO}

A responsabilização das pessoas jurídicas por atos abrangidos naquilo que vulgarmente se chama de corrupção representa um tema de estudo em intenso e necessário desenvolvimento, suscitando debates e os mais diversos posicionamentos na academia mundial, sobretudo nacionalmente após a promulgação da Lei $\mathrm{n}^{\circ}$ 12.846/13, popularmente conhecida como "Lei Anticorrupção”. Esta não representa grande inovação tipicamente brasileira, tendo em vista que foi antecedida por demandas internacionais direcionadas à necessidade de melhor tratamento jurídico para as hipóteses de criminalidade empresarial, especialmente relevante com a globalização econômica que marca o cenário atual (SAAD-DINIZ, 2014, pp. 112-113).

O mérito do referido marco legal está em estabelecer um sistema de responsabilização, nas esferas administrativa e penal, destinado aos atos praticados por pessoas jurídicas, ou até mesmo entes coletivos despersonalizados. Tendo por centro a figura da responsabilidade objetiva, o sistema mencionado se volta diretamente à pessoa jurídica, independentemente da eventual responsabilização das pessoas físicas que a componham.

Revela-se imprescindível, pela leitura dos termos da Lei $n^{0} 12.846 / 13$, o estudo do conceito de responsabilidade objetiva, bem como os critérios normativos para sua verificação em relação às pessoas jurídicas. Preceitua o artigo $2^{\circ}$ daquele diploma que haverá a responsabilidade objetiva quando verificado que o ato lesivo foi praticado no interesse da pessoa jurídica ou em seu benefício, alternativa ou cumulativamente.

No presente artigo, centrar-se-á no critério normativo de interesse da pessoa jurídica para a caracterização de sua responsabilidade objetiva. O referido recorte é extremamente relevante para o estudo da responsabilização da pessoa jurídica pois, uma vez verificada a existência de interesse do ente coletivo na prática do ato lesivo, seria possível sua responsabilização independentemente da existência de efetivo benefício gerado como parte de seus resultados.

O recorte metodológico terá por centro, ainda, o conceito de interesse no âmbito da sociedade anônima, a qual é regida pela Lei ${ }^{\circ}$ 6.404/76, com especificidade e minúcias acerca do tema das quais os demais tipos societários e de organizações de pessoas jurídicas não dispõem em igual dimensão. Ainda, os estudos acerca do conflito de interesses atraíram grande debate e originaram profícuos estudos sobre o tema dentro do contexto das sociedades anônimas. 
Será feita também a abordagem do tema do compliance nas sociedades anônimas, centrando as discussões no conceito do interesse para a responsabilização da pessoa jurídica, e analisando o conflito de interesses como objeto de atenção de programas de compliance.

Considerando o material reunido, os conceitos e os argumentos alinhados neste artigo, fez-se uma breve crítica a respeito da Lei $n^{0} 12.846 / 13$ e a sua forma de aplicação às sociedades anônimas brasileiras. Buscou-se, unindo estudos não apenas de direito penal, como também fundamentos de direito societário e empresarial, traçar o modo mais adequado de lidar com o tema do interesse nas sociedades anônimas com a finalidade de atender aos objetivos da Lei $n^{\circ}$ 12.846/13 no combate à corrupção e na instituição de programas de compliance.

\section{DO SISTEMA DE RESPONSABILIZAÇÃO DOS ENTES COLETIVOS PRIVADOS NA LEI No 12.846/13}

Atendendo a demandas internacionais, no intuito de passar a preencher um espaço que ainda se via pouco explorado na regulação da improbidade em relações público-privadas no Brasil, qual seja, a responsabilização sistemática dos próprios entes coletivos privados por comportamentos abrangidos naquilo que amplamente se chama de “corrupção”, é que a Lei nº 12.846/13 veio a tratar da responsabilidade administrativa e civil de pessoas jurídicas pela prática de atos contra a administração pública, nacional ou estrangeira.

Na tentativa de lidar com a corrupção no contexto de sua complexidade, a popularmente denominada “Lei Anticorrupção”, ou “Lei da Empresa Limpa”, ofereceu um sistema de responsabilização em duas esferas de caráter processual, no caso administrativa e judicial, composto de duas naturezas materiais: administrativa e civil.

A responsabilização na esfera processual administrativa estabelece um processo administrativo para aplicação de uma sanção de natureza administrativa, consistente em multa no valor de 0,1\% a $20 \%$ do faturamento bruto do último exercício anterior ao da instauração do processo; e/ou a publicação extraordinária da decisão condenatória (artigos $6^{\circ}$ e $7^{\circ}$ da Lei nº 12.846/13). Já na responsabilização processual judicial, foram determinadas sanções, que seriam de natureza material civil, a serem julgadas e aplicadas através do procedimento previsto para a Ação Civil Pública (artigo 21 da Lei ${ }^{\circ}$ 12.846/13), e que consistem em perdimento de bens, suspensão ou interdição parcial de suas atividades, e dissolução compulsória da pessoa jurídica (artigo 19 da Lei ${ }^{\circ}$ 12.846/13). 
Ainda neste contexto, o Ministério Público tem legitimidade para requerer a aplicação das ditas sanções administrativas previstas no artigo $6^{\circ}$ da Lei, caso haja a omissão das autoridades competentes para promover a responsabilização administrativa (artigo 20 da Lei no 12.846/13). Também no âmbito processual da responsabilização judicial, há ainda um reforço na previsão de responsabilidade civil, em sua forma material típica do Código Civil, consistente na reparação integral de eventual dano causado (artigo 21, parágrafo único, da Lei nº 12.846/13). Apesar da utilização de esferas processuais e naturezas materiais distintas, o sistema de responsabilização disposto tem como base fundamental a responsabilidade objetiva das pessoas jurídicas (artigo $2^{\circ}$ da Lei $n^{\circ} 12.846 / 13$ ) por atos tipificados como lesivos pela própria Lei (artigo $5^{\circ}$ da Lei $n^{\circ} 12.846 / 13$ ). É dizer que configurada uma ou mais das condutas tipificadas na Lei, incide-se a responsabilidade objetiva da pessoa jurídica envolvida, sendo tal responsabilidade levada então às diferentes esferas processuais e sanções estabelecidas.

Logo, a responsabilidade objetiva da pessoa jurídica pela configuração da conduta lesiva tipificada é o centro do sistema de responsabilização criado pela Lei, sendo então os processos e procedimentos utilizados, e as sanções aplicadas, consequências jurídicas do sistema.

Dado o objeto proposto neste trabalho, e o fato de ser a responsabilidade objetiva a verdadeira chave de ignição do sistema de responsabilização, cumpre então estudá-la em específico, buscando seus delineamentos normativos.

\subsection{DA RESPONSABILIDADE OBJETIVA DAS PESSOAS JURÍDICAS POR ATOS LESIVOS}

Em contrapartida à centralidade da responsabilidade objetiva para a Lei Anticorrupção, esta teceu apenas um artigo que ofereceria efetivamente algum delineamento ao critério objetivo, no caso o seu artigo $2^{\circ}$ : “as pessoas jurídicas serão responsabilizadas objetivamente, nos âmbitos administrativo e civil, pelos atos previstos nesta Lei praticados em seu interesse ou benefício, exclusivo ou não".

Parte da doutrina tem entendido como referencial teórico utilizado pela Lei para a responsabilidade objetiva, sobretudo no plano da responsabilização civil, a Teoria do Risco, de forma que aqueles entes privados que se propõem a ter uma relação público-privada apresentam 
riscos de corrupção, inerentes à esta condição, os quais estariam assumindo (DI PIETRO; MARRARA, 2017, p. 30).

Outros fatores determinantes em relação à opção pela responsabilidade objetiva são a dificuldade teórica, e até mesmo prático-probatória, da constatação do elemento subjetivo nos entes coletivos; e um certo incentivo à implantação por estes entes de programas de compliance (DI PIETRO, 2017, p. 30).

Ainda que seja expressa a responsabilidade objetiva, Maurício Zockun (2017), apoiando-se na Teoria da Ficção das pessoas jurídicas, entende que não há como se caracterizar a responsabilidade objetiva sem a constatação do elemento subjetivo das pessoas físicas envolvidas. As pessoas jurídicas atuariam no mundo fenomênico sempre representadas através de pessoas naturais. E as condutas previstas no artigo $5^{\circ}$ da Lei da Empresa Limpa seriam todas de prática eminentemente dolosa, sem a possibilidade de ser cometida de outra forma (DI PIETRO; MARRARA, 2017, pp. 15-19).

Logo, a própria caracterização do cometimento dos atos ilícitos tipificados na Lei necessitaria do elemento subjetivo das pessoas físicas envolvidas, pela própria natureza das condutas, para que então pudesse ser atribuída responsabilidade objetiva à pessoa jurídica representada.

Concorda-se aqui em parte com este raciocínio. Com efeito, a conduta dolosa da pessoa física envolvida deve, em geral, levar à responsabilidade objetiva da pessoa jurídica representada, como que uma extensão da responsabilidade, quando presentes os critérios normativos do interesse e do benefício.

No entanto, a complexidade funcional de determinados entes coletivos pode dificultar a individualização da conduta dos vários agentes envolvidos em determinados casos, de modo que a prática de alguns dos atos ilícitos previstos na Lei Anticorrupção seja executada de modo fracionado, em que cada pessoa física age sem um necessário (ou identificável) dolo, ou até mesmo culpa.

A Teoria da Ficção por si só é insuficiente a tais questões de responsabilização, já que por vezes o ato lesivo se compreende em uma dinâmica real e própria do ente coletivo em seu contexto institucional, podendo representar a conduta de um departamento como todo, e não necessariamente na ação de um individual, ou mesmo na ação individualizada de um grupo, de forma que o dolo se dissipa no trâmite da prática da conduta.

Exemplo nesse sentido vem a ser a conduta descrita pelo artigo $5^{\circ}$, inciso II, que trata do financiamento, custeio ou patrocínio de prática dos próprios atos lesivos previstos na Lei. Neste 
caso, é possível que aquele que faça o efetivo pagamento sequer tenha real noção do seu destino, que aquele que tenha contato direto com o representante de um agente público não saiba desta condição do representado, e que aquele que estabeleceu um efetivo acordo de propina (corrupção passiva) não seja identificado. Comprova-se a transferência dos valores, comprovase o interesse ou o benefício, comprova-se o objetivo da subvenção de atos lesivos, mas não se identifica um necessário elemento volitivo.

Assim, não há como se retirar do sistema de responsabilização a necessária relação entre uma conduta dolosa de uma pessoa natural, e a consequente responsabilidade objetiva da pessoa jurídica. Ainda que se critique a escolha feita pelo sistema da Lei, o elemento subjetivo é claramente irrelevante à responsabilização da pessoa jurídica, devendo se ver constatados apenas os critérios normativos de imputação objetiva.

A responsabilidade objetiva proferida na Lei envolve, de forma expressa, dois critérios normativos já citados, dispostos de forma alternativa: o interesse ou benefício da pessoa jurídica, exclusivo ou não. O primeiro critério é aquele que se apresenta como objeto fundamental deste trabalho.

Em razão do caráter alternativo conferido pela Lei aos critérios objetivos, a realização do ato lesivo no interesse da pessoa jurídica não é sempre necessária à responsabilidade objetiva, bastando que se veja configurado o simples benefício do ente coletivo. Da mesma forma, basta a realização da conduta no interesse do ente coletivo, mesmo que não se veja configurado benefício.

Ainda que não seja imprescindível à configuração da responsabilidade objetiva, o interesse surge com papel de destaque, já que a sua configuração no eventual ato lesivo cometido permite a responsabilização mesmo que não tenha havido qualquer vantagem concreta ao ente coletivo. Entretanto, o interesse é critério de conceito abrangente e historicamente controverso, podendo ainda se distinguir entre os diferentes entes coletivos privados existentes, sendo imperioso o seu desenvolvimento doutrinário para uma aplicação mais segura do dispositivo legal. Em razão disso, é que se passa a análise do interesse como critério normativo.

\section{DO INTERESSE COMO CRITÉRIO NORMATIVO}

Segundo José Roberto Pimenta Oliveira (2017), o interesse preconizado pelo artigo $2^{\circ}$ da Lei Anticorrupção representa critério objetivo funcional, resultado objetivo (e não psicológico) 
buscado pela conduta ilícita. Por outro lado, o benefício perfaria critério objetivo material, de modo que se constituiria em um real efeito benéfico ou ampliativo obtido, ou até mesmo pretendido com o ato lesivo praticado (DI PIETRO; MARRARA, 2017, p. 32).

Aceita-se aqui a distinção realizada pelo Autor supracitado, com apenas uma ressalva: a não configuração do benefício apenas como efeito benéfico pretendido com o ato lesivo praticado. Como critério objetivo material, o benefício deve se constituir em vantagem apenas obtida, de modo que a pretensão de benefício deve permanecer no campo do interesse como critério objetivo funcional.

Afinal, se admitida a configuração do critério benefício através da simples pretensão, tal pretensão necessita de corpo, a ser permeado pelo interesse, e não apenas da vontade psicológica do agente, sob pena de punição do ente coletivo a partir da simples alegação de que eventual resultado lhe seria direcionado.

Tendo isto em vista, duas seriam as hipóteses alternativas de responsabilidade objetiva da pessoa jurídica a partir dos critérios objetivos: a realização do ato com uma pretensão permeada pelo interesse do ente coletivo; ou o efetivo aferimento de vantagem ao ente coletivo a partir do ato lesivo. Em outras palavras, ou o ato se prestava a atingir seus objetivos advindos de seu interesse, ou o ato lhe resultou reais benefícios. Por óbvio, cabe também a cumulação das duas hipóteses.

Logo, no plano da pretensão, o delineamento objetivo se dá pelo interesse do ente coletivo. Mas o que exatamente abrange o interesse do ente coletivo?

$\mathrm{O}$ artigo $1^{\circ}$, parágrafo único, da Lei $\mathrm{n}^{\circ} 12.846 / 13$, que determina a aplicabilidade de seus dispositivos, cita uma diversidade de molduras jurídicas de entes coletivos de natureza privada, os quais podem representar desde uma grande sociedade anônima de capital aberto, até uma pequena associação de atendimentos beneficentes, por exemplo. É fácil constatar, mesmo intuitivamente, que os interesses das pessoas jurídicas nesses casos podem ser severamente distintos.

Dada a distinção que os interesses podem tomar a partir dos diversos tipos de entes coletivos privados, fez-se aqui a opção metodológica pela análise da abordagem doutrinária do interesse no contexto das sociedades anônimas, buscando-se emoldurar, ao menos neste tipo societário, o que pode ser considerado interesse para fins de punição pela Lei Anticorrupção. 


\subsection{DO INTERESSE DA COMPANHIA NO CONTEXTO DAS SOCIEDADES ANÔNIMAS}

Definir o que seria o interesse de uma sociedade anônima, o chamado interesse social, exige abordar diversas teorias doutrinárias construídas com o intuito de precisar como se daria sua formação. Em seu estudo, o corpo de acionistas da sociedade é relevante, bem como a forma com que é concebida e considerada a relação entre eles, e perante a própria pessoa jurídica. Ainda, o papel da sociedade anônima no contexto social e econômico em que se insere também são fatores a influenciar a formação do interesse social.

Iniciando pelas teorias clássicas, tem-se a dualidade entre o posicionamento contratualista e o institucionalista. Muito embora tenham sido elaboradas em contexto econômico e social profundamente diverso do atual, conservam o mérito de formularem as bases do estudo do interesse social.

Segundo a corrente contratualista, tem-se como ponto central o entendimento de que o interesse social seria equivalente, coincidente com a soma dos interesses de cada um dos acionistas, seu interesse comum. A sociedade anônima seria então concebida como uma relação contratual entre seus acionistas. (FRANÇA, 2014, pp. 42-44)

Há, contudo, distinções e nuances sobre o que se entende por interesses dos sócios (SALOMÃO FILHO, 2006, pp. 25-26). Inevitavelmente, a esfera de interesses de um indivíduo que compõe uma sociedade anônima não se restringe a ela, abarcando, por exemplo, interesses relativos à sua vida privada e pessoal. Por essas razões, é necessário precisar que apenas o interesse do sócio enquanto sócio, deve ser considerado na definição do interesse social: somente os interesses decorrentes do status socii são relevantes. (FRANÇA, 2014, pp. 42-44)

Quanto à definição do que precisamente seria o corpo de sócios para fins de identificação do interesse social, tem-se a discussão sobre se deveriam ser considerados apenas os membros atuais de uma sociedade ou se potenciais membros futuros deveriam também ser equacionados. Em relação aos mencionados sócios futuros, seria necessário definir também qual seria seu interesse enquanto sócios: discutiu-se se seu interesse comum seria pela eficiência da sociedade, a distribuição de lucros, ou uma solidariedade entre seus interesses individuais. (FRANÇA, 2014, pp. 44-47)

Fundamentando-se em doutrina italiana, principalmente em Jaeger, contudo, alerta França (2014) para as implicações dessas definições contratualistas. A título de exemplo tem-se a 
virtual impossibilidade de conflito entre um acionista e o interesse social. Ainda, menciona-se a aproximação aos preceitos institucionalistas ao se afirmar a existência de um interesse social específico e imutável independentemente do corpo de acionistas, tornando irrelevante a figura à qual o referido interesse é atribuído. (FRANÇA, 2014, pp. 44-45)

Nesse diapasão, a teoria institucionalista se apresenta a definir o interesse social como expressão de vontade própria da sociedade, o que, para Gierke, atribuiria realidade ao fenômeno associativo, razão pela qual essa teoria é denominada também de realista (SALOMÃO FILHO, 2014, pp. 289-290).

Concebida como instituição, a sociedade teria sua existência jurídica independente do conjunto de acionistas que a componha ou venha a compor, dotada de órgãos necessários para o cumprimento de suas finalidades, com manifestações de vontade produzidas a partir da atuação de seus membros. Supera-se, assim, o conceito de interesse social limitado à esfera delimitada pelo interesse comum dos sócios, pelo conjunto de seus interesses, em relação ao qual o interesse social seria superior. (FRANÇA, 2014, pp. 36-38)

Com base nessa teoria, justifica-se a atribuição de personalidade a um fenômeno associativo, o que não se restringe mais aos seres humanos. O processo de formação dessa vontade própria da sociedade, a definição do interesse social não mais se concebe em termos e medidas do corpo de membros que a constitua (SALOMÃO FILHO, 2014, pp. 290-291).

A conceituação de interesse social deve observar, ainda, o contexto atual de desenvolvimento e globalização econômica, o que influencia a própria concepção do que representa a sociedade anônima.

Nesse aspecto, contribui a análise econômica do direito para seu entendimento. Considerando as diferentes operações econômicas realizadas em mercado, Coase (1937) ressalta que seu equilíbrio e fluxo é ditado pelo mecanismo autossuficiente de preços, de modo que a sociedade passa a funcionar coordenadamente como um organismo. Justamente as trocas e transações realizadas livremente em mercado entre os diferentes agentes econômicos ditariam os preços e custos de cada operação.

A organização, dentro de uma empresa, de todas a operações necessárias ao desempenho de uma atividade, portanto, eliminaria o custo de sua realização em livre mercado. Em lugar de sua complexa estrutura, haveria uma coordenação central das operações pelo empreendedor, superando o mecanismo de preços e minimizando os custos por eles impostos mediante o 
obstáculo de identificar quais os preços relevantes para cada transação. (COASE, 1937, pp. 387-392)

O número de contratos cuja celebração é necessária para a realização da atividade da empresa é reduzido, eliminando-se aqueles atinentes a operações agora organizadas em sua estrutura interna, não mais em mercado (ALCHIAN; DEMSETZ, 1972, pp. 783-785). A empresa então poderia ser concebida como um "feixe de contratos" a organizar sua atividade. (COASE, 1937, pp. 387-392)

A partir da perspectiva econômica apresentada, tem-se, diferentemente das teorias clássicas supramencionadas, que o interesse social não poderia ser definido em termos fixos. A esfera, a amplitude dos interesses, internos e externos, envolvidos para a definição de um interesse atribuível à sociedade anônima é mais diversa do que as teorias clássicas poderiam abarcar.

Nesse contexto, é imprescindível referirmo-nos também à teoria do contrato plurilateral de Ascarelli (1999), cuja função econômica seria de organização ${ }^{3}$, sendo o contrato de sociedade uma subespécie dos contratos plurilaterais. Como contrato-organização, a sociedade não se destinaria ao cumprimento de diferentes interesses orientados a uma mesma finalidade: haveria um interesse societário, social, próprio, destacado e independente do interesse individual dos membros da sociedade. (SALOMÃO FILHO, 2014, p. 328)

Para a adequada definição desse interesse social, portanto, seria necessário definir quais interesses são passíveis ou não de interiorização pela estrutura da sociedade. Conformar-se-ia, assim, uma "noção procedimental da sociedade e do interesse social” (SALOMÃO FILHO, 2014, pp. 328-330).

Salienta Salomão Filho (2014), ainda, que não há, na Lei n ${ }^{\circ}$ 6.404/76, a previsão de um critério teórico definido para a correta distinção entre os interesses potencialmente interiorizáveis. Seria então necessário analisar, empiricamente, cada um dos interesses e sua relação com os societários. Mesmo assim, haveria elementos comuns a definir um possível critério de internalização, pela teoria da cooperação.

A referida teoria parte do pressuposto de que, para comporem a mesma estrutura societária, é necessário que os interesses sejam organizados de modo a eliminar possíveis conflitos. Para possibilitar a cooperação entre eles, três requisitos precisariam ser verificados: haver apenas uma pequena quantidade, acesso a informações suficientes e continuidade da relação

\footnotetext{
3 A adotar este posicionamento menciona-se também Verçosa (2010), Salomão Filho (2006) e (2014), e D. Zylbersztajn (2002).
} 
(SALOMÃO FILHO, 2014, p. 329). A sociedade anônima então seria caracterizada como uma organização (contrato-organização) a operar a internalização de interesses e a solução do conflito entre eles.

Tal posicionamento, então, reconhece a existência de diferentes interesses interdependentes a compor o interesse societário, não limitado ao conjunto dos interesses dos acionistas. A título de exemplo, os interesses de consumidores, trabalhadores e investidores também seriam contemplados, com a peculiaridade da comunhão de interesses operada na sociedade ser orientada a uma finalidade, um escopo comum, social.

As teorias construídas para a definição do interesse social, no âmbito societário, sustentam a tarefa de sua execução prática como árdua e desafiadora. Mesmo assim, trata-se de um caminho que precisa ser desbravado, sobretudo considerando-se que o interesse social é um dos critérios normativos para a verificação de responsabilidade objetiva da pessoa jurídica nos termos do artigo $2^{\circ}$ da Lei $n^{\circ} 12.846 / 13$.

Não sendo possível previamente determinar qual a magnitude dos interesses a serem internalizados e considerados pela sociedade anônima na formação de seu interesse social, resta a saída de, procedimentalmente, identificar no contexto do ato lesivo investigado o interesse pertinente a ser internalizado, e se este se viu como escopo, exclusivo ou não, da conduta pratica; e, no âmbito preventivo preconizado pela Lei Anticorrupção, construir ferramentas que garantam que a constituição do interesse social não seja viciada, e nem sirva de objeto para condutas ilícitas tipificadas.

Nesse contexto assumem grande relevância os estudos acerca do conflito de interesses nas sociedades anônimas, sobretudo no âmbito do exercício do direito de voto pelos acionistas em assembleia geral, na qual os rumos da sociedade e de suas atividades podem ser alterados.

\section{COMPLIANCE E RESPONSABILIDADE OBJETIVA SOB A PERSPECTIVA DO INTERESSE}

Também buscando seguir a tendência internacional, a qual já vinha se refletido internamente através da Lei no 9.613/98 (Lei da Ocultação de Bens), a Lei nº 12.846/13 trouxe a previsão de programas de integridade (compliance), claramente como um instrumento a ser utilizado na tentativa de se lidar com atos de improbidade contra a Administração Pública cometidos por entes coletivos privados. 
Compliance se refere, basicamente, ao estabelecimento de padrões internos de acordo e em cumprimento de dados normativos no âmbito do desenvolvimento das atividades de um ente coletivo (SILVEIRA; SAAD-DINIZ, 2015, p. 65).

Trata-se de um modelo de autorregulação do ente coletivo privado o qual, na medida em que é feito com base em parâmetros legais, e toma relevância jurídica quando da responsabilização deste mesmo ente, constitui modelo regulatório de corregulação público-privada, também chamado de autorregulação regulada (SILVEIRA; SAAD-DINIZ, 2015, p. 69). Em outras palavras, é estabelecida uma inteiração entre a regulação pública e a autorregulação privada.

A louvável tentativa da Lei $\mathrm{n}^{0}$ 12.846/13 se fundamenta na ideia de através de programas de compliance iniciar uma possível cultura de integridade, além de se estabelecer uma corregulação entre os entes públicos e privados, dada a dificuldade de si lidar com a corrupção caracterizada pela alta e complexa clandestinidade.

Contudo, o legislador quedou inexpressivo o incentivo à adesão dessas estruturas de conformidade, na medida em que estabeleceu a presença de mecanismos de integridade no ente privado apenas como fator a ser levado em consideração na aplicação da sanção, e não na própria responsabilização. Ou seja, no bojo do ato lesivo praticado, o programa de compliance não será considerado a definir ou não a própria responsabilidade do ente coletivo privado, mas apenas a permitir a atenuação (até mesmo total), da consequência jurídica que lhe será direcionada.

Tal incentivo se demonstra relativamente inócuo tendo em vista que da forma como estabelecido o compliance dentro do sistema de responsabilização, permanece-se a possibilidade de que todo o investimento de um ente coletivo privado em um programa de integridade, dentro dos parâmetros legais, possa vir a ser até mesmo irrelevante à responsabilização, ou ao menos levar à uma atenuação não condizente com o esforço da pessoa jurídica envolvida (SARCEDO, 2016, p. 134).

De todo modo, o compliance não deixa de se fazer valer como uma importante opção de maior segurança aos entes coletivos privados, sobretudo aos que mais se colocam ao risco das relações público-privadas, em face da severa e incerta responsabilidade objetiva determinada.

No esforço de se trazer uma maior palpabilidade à responsabilidade objetiva estabelecida pela Lei através do critério normativo do interesse, observou-se no contexto das sociedades anônimas a amplitude do conceito de interesse social, sendo objeto a que não se cabe definição fixa, mas sim construtiva. 
E tomando por base as teorias societárias apontadas, a instituição de programas de compliance pode ser essencial à garantia de que o interesse social seja validamente formado. Consequentemente, havendo adequada formação do interesse social, as situações de caracterização da responsabilidade objetiva da sociedade anônima serão delimitadas de maneira mais clara e precisa, permitindo melhor manusear os riscos envolvidos.

Nesse sentido, utilizando-se da perspectiva da formação do interesse social tanto para a verificação da responsabilidade objetiva, quanto para atitudes preventivas atinentes à autorregulação do ente coletivo privado, é relevante abordar o tema do conflito de interesses, situação prevista pelo artigo $115, \S 1^{\circ}$ da Lei $n^{\circ} 6.404 / 76$.

Preceitua o referido dispositivo que o acionista não poderá exercer seu direito de voto nas assembleias gerais sempre se tiver interesses individuais conflitantes com o interesse social, sendo necessário o estudo das teorias existentes sobre o conflito de interesses.

\subsection{DO CONFLITO DE INTERESSES COMO OBJETO DE COMPLIANCE}

Considerando que o exercício do direito de voto do acionista nas assembleias gerais contribui para o direcionamento das atividades da sociedade anônima e a consequente observância de seu interesse social, é de profunda importância que cada voto o observe. As hipóteses de conflito de interesses entre acionistas e sociedade anônima então se encontram intimamente relacionadas à expressão do interesse social, o que influencia as hipóteses de responsabilidade objetiva da pessoa jurídica.

A previsão do artigo 115, $\$ 1^{\circ}$ da Lei n ${ }^{\circ} 6.404 / 76$ a determinar que o acionista não poderá votar nas assembleias gerais quando tiver algum interesse particular a se chocar com o interesse social gerou inúmeros debates doutrinários sobre o tema do conflito de interesses, os quais culminaram em duas teorias principais. A teoria do conflito material e a teoria do conflito formal de interesses polarizam as discussões, às quais devem ser incorporados os estudos atuais acerca das demandas do mercado e de suas características.

A teoria do conflito material de interesses preceitua que somente após proferido o voto e verificado efetivo dano dele decorrente, em prejuízo da sociedade ou dos demais acionistas, seria possível constatar a existência de conflito. Nesta hipótese, haveria um abuso do direito de voto, recorrendo-se ao caput do artigo 115 da Lei $n^{\circ}$ 6.404/76 para sua definição como a 
contrariedade ao interesse social, este entendido como a soma dos interesses dos sócios. (CARVALHOSA, 1998, pp. 444-445)

Segundo a teoria do conflito formal de interesses, por outro lado, haveria uma efetiva proibição, impedimento, de voto em desfavor de qualquer acionista que se encontre em posição contrastante ao da sociedade. A verificação do conflito seria então feita antes de proferido o voto ou de causado efetivo prejuízo à sociedade. Como sanção, haveria a automática nulidade do voto proferido.

A respeito da definição de qual das duas teorias seria a mais adequada, Salomão Filho (2014) ressalta a importância de se contribuir para a formação de um ambiente societário mais cooperativo. Para analisar a influência do relacionamento interindividual sobre o comportamento individual, então recorre à moderna teoria dos jogos. Nela dois elementos devem ser considerados: a reputação dos agentes e o tipo de integração entre eles.

O tipo de comportamento esperado de um agente e o nível de confiança que nele podem ser depositados são definidos por sua reputação. Em adição, o tipo de integração delineia o resultado de seu comportamento, se haverá ganhos ou perdas: em um jogo de soma zero, a perda de um agente corresponde exatamente ao ganho de outro. Nesse contexto, a regra do conflito formal de interesses contribuiria para a formação de um ambiente mais cooperativo, uma vez que influencia ambos os elementos.

Sobre a reputação do agente, a regra do conflito formal de interesses o impediria, ex ante, de sequer exercer seu direito de voto quando se encontrar em situação de potencial contraste ao interesse social. Desta forma, não haveria a possibilidade de formação de uma conduta individualista em prejuízo da coletividade e da reputação do agente. A cooperação seria estimulada, ainda, pelo fato de não haver ganhos a um agente às custas dos prejuízos aos demais, resultando em jogo de soma diferente de zero.

Com base nesse posicionamento, a própria organização de interesses a marcar a sociedade anônima seria privilegiada. A confiança de agentes externos, como investidores, seria privilegiada, fator este de extrema importância, sobretudo quando considerado o alto grau de concentração de controle verificado nas companhias brasileiras (SALOMÃO FILHO, 2008, p. 128).

Desta forma, o procedimento a ser seguido para a expressão do interesse social deve ser construído de forma a evitar quaisquer possibilidades de vício por conflito de interesses. A instituição de programas de compliance a contemplar especialmente as regras e os 
procedimentos para o exercício do direito de voto em minúcias mais atentas que as contidas na previsão legal do conceito contribuiria para a melhor organização interna da sociedade anônima.

Garantindo uma expressão do interesse social isenta de meandros particulares de quaisquer acionistas, favorece-se planejamento mais adequado quanto aos riscos da atividade. Ainda, permite maior clareza quanto à configuração da responsabilidade objetiva em função de atos lesivos praticados no interesse da sociedade anônima. O tratamento do conflito de interesse indubitavelmente, portanto, deve ser abarcado nas atividades da estrutura de compliance.

\section{CONSIDERAÇÕES FINAIS}

O sistema de responsabilização da pessoa jurídica estabelecido pela Lei no 12.846/13 tem como principal gatilho a responsabilidade objetiva por atos lesivos tipificados, baseada, segundo a doutrina, na Teoria do Risco, entendendo-se a corrupção como um risco inerente da relação entre os entes públicos e privados.

Tal responsabilidade objetiva, ao ignorar o elemento subjetivo da conduta atribuída à pessoa jurídica, requer apenas a caracterização da conduta e do nexo de causalidade, além de dois critérios normativos de imputação objetiva, alternativos ou cumulativos, calcados no interesse e no benefício, exclusivos ou não.

O interesse, como critério estabelecido pelo artigo $2^{\circ}$ da Lei ${ }^{\circ} 12.846 / 13$, é entendido como critério objetivo funcional, sendo o resultado objetivo (e não psicológico) buscado pela conduta ilícita. Tendo em vista a amplitude e complexidade do conceito de interesse no contexto de uma pessoa jurídica, é necessário o seu desenvolvimento a permitir uma aplicação prática e pertinente aos objetivos da Lei Anticorrupção, trazendo um maior delineamento à incerta e ainda extremamente controversa responsabilidade objetiva determinada.

No estudo das diversas frentes que se propuseram a desenvolver o conceito do interesse social no âmbito das sociedades anônimas, concluiu-se pela pertinência da noção procedimental da sociedade e do interesse social, e da teoria da cooperação no âmbito da teoria do contratoorganização.

Aplicando tais noções ao contexto da Lei $n^{\circ}$ 12.846/13, tem-se que adotando a impossibilidade de se determinar de forma prévia e fixo a magnitude dos interesses a serem internalizados e considerados pela sociedade anônima na formação de seu interesse social, resta a saída de, 
procedimentalmente, identificar no contexto do ato lesivo investigado o interesse pertinente a ser internalizado, e se este se viu como escopo, exclusivo ou não, da conduta pratica; e, no âmbito preventivo preconizado pela Lei Anticorrupção, construir ferramentas que garantam que a constituição do interesse social não seja viciada, e nem sirva de objeto para condutas ilícitas tipificadas.

Mesmo que de forma ainda modesta, a Lei $n^{0}$ 12.846/13 adotou um modelo de corregulação público-privada, colocando o programa de compliance entre os fatores a serem analisados na aplicação de sanções, com a possibilidade de até mesmo se retirar a responsabilidade da pessoa jurídica.

Constatada a relevância do interesse da pessoa jurídica para a responsabilização objetiva por atos lesivos, e a relação próxima entre a responsabilidade objetiva e o compliance para um caminho de integridade dos entes coletivos, conclui-se que a construção e a preservação íntegra do interesse social das sociedades anônimas deve ser preocupação central dos programas de conformidade, o qual pode se utilizar do conflito formal de interesses como objeto nesse caminho construtivo, e preventivo.

\section{REFERÊNCIAS}

ALCHIAN, Armen A.; DEMSETZ, Harold. Production, information costs and economic organization. American Economic Review, v. 62, n. 5, 1972. Disponível em: http://www.jstor.org/stable/1815199. Acesso em: 25 mar. 2018.

ASCARELLI, Tullio. Problemas das sociedades anônimas e direito comparado. São Paulo: Quorum, 2008.

CARVALHOSA, Modesto. Comentários à lei de sociedades anônimas. v. 2, 2. ed. São Paulo: Saraiva, 1998.

COASE, Ronald Harry. The nature of the firm. Economica, New Series, v. 4, n. 16, nov. 1937, p. 387-392. Disponível em: http://www.jstor.org/stable/pdf/2626876.pdf?acceptTC=true. Acesso em: 04 jul. 2015.

COMPARATO, Fábio Konder; SALOMÃO FILHO, Calixto. O poder de controle na sociedade anônima. 6. ed. Rio de Janeiro: Forense, 2014. 
DI PIETRO, Maria Sylvia Zanella; MARRARA, Thiago (coord.). Lei anticorrupção comentada. Belo Horizonte: Fórum, 2017.

FRANÇA, Erasmo Valladão e Novaes. Conflito de interesses nas assembleias de S.A. 2. ed. São Paulo: Malheiros, 2014.

SAAD-DINIZ, Eduardo. A criminalidade empresarial e a cultura de compliance. Revista Eletrônica de Direito Penal AIDP-GB, ano 2, vol. 2, n. 2, p. 112-120, 2014.

SALOMÃO FILHO, Calixto. O novo direito societário. 3. ed. São Paulo: Malheiros, 2006. , Regulação da atividade econômica. 2. ed. Malheiros: São Paulo, 2008.

SARCEDO, Leandro. Compliance e responsabilidade penal da pessoa jurídica: construção de um novo modelo de imputação baseado na culpabilidade corporativa. São Paulo : LiberArs, 2016.

SILVEIRA, Renato de Mello Jorge; SAAD-DINIZ, Eduardo. Compliance, direito penal e lei anticorrupção. São Paulo: Saraiva, 2015.

VERÇOSA, Haroldo Malheiros Duclerc. Curso de direito comercial - Teoria geral das sociedades - Sociedades em espécie. v. 2, 2. ed., São Paulo: Malheiros, 2010.

ZYLBERSZTAJN, Décio. Quatro estratégias fundamentais para cooperativas agrícolas, in BRAGA, Marcelo Jorge; REIS, Brício dos Santos (Org.), Agronegócio cooperativo: reestruturação e estratégias. Viçosa: Suprema, 2002. 